IZA DP No. 6316

Sabotage in Tournaments:

Evidence from a Natural Experiment

Loukas Balafoutas

Florian Lindner

Matthias Sutter

January 2012 


\title{
Sabotage in Tournaments: Evidence from a Natural Experiment
}

\author{
Loukas Balafoutas \\ University of Innsbruck \\ Florian Lindner \\ University of Innsbruck \\ Matthias Sutter \\ University of Innsbruck, University of Gothenburg, \\ CESifo and IZA
}
Discussion Paper No. 6316
January 2012

IZA
P.O. Box 7240
53072 Bonn
Germany

Phone: +49-228-3894-0

Fax: +49-228-3894-180

E-mail: iza@iza.org

\begin{abstract}
Any opinions expressed here are those of the author(s) and not those of IZA. Research published in this series may include views on policy, but the institute itself takes no institutional policy positions.

The Institute for the Study of Labor (IZA) in Bonn is a local and virtual international research center and a place of communication between science, politics and business. IZA is an independent nonprofit organization supported by Deutsche Post Foundation. The center is associated with the University of Bonn and offers a stimulating research environment through its international network, workshops and conferences, data service, project support, research visits and doctoral program. IZA engages in (i) original and internationally competitive research in all fields of labor economics, (ii) development of policy concepts, and (iii) dissemination of research results and concepts to the interested public.
\end{abstract}

IZA Discussion Papers often represent preliminary work and are circulated to encourage discussion. Citation of such a paper should account for its provisional character. A revised version may be available directly from the author. 


\section{ABSTRACT}

\section{Sabotage in Tournaments: Evidence from a Natural Experiment ${ }^{*}$}

Many tournaments are plagued by sabotage among competitors. Typically, sabotage is welfare-reducing, but from an individual's perspective an attractive alternative to exerting positive effort. Yet, given its illegal and often immoral nature, sabotage is typically hidden, making it difficult to assess its extent and its victims. Therefore, we use data from Judo World Championships, where a rule change in 2009 basically constituted a natural experiment that introduced one costless opportunity for sabotage. In Judo, competitors can break an opponent's attack in an unsportsmanlike manner; these are seen as acts of sabotage. Based on a unique dataset of 1,422 fights, we find that the rule change in 2009 has led to a large increase in the use of sabotage. Moreover, sabotage is more likely to be employed by relatively less qualified individuals, and to be targeted at more qualified ones. From a survey among spectators, we show that sabotage is welfare-reducing.

JEL Classification: C93, D03, L83, M51, M52

Keywords: $\quad$ tournaments, sabotage, Judo, natural experiment

Corresponding author:

Matthias Sutter

University of Innsbruck

Department of Economics

Universitaetsstrasse 15

6020 Innsbruck

Austria

E-mail: matthias.sutter@uibk.ac.at

\footnotetext{
* We thank Gary Charness, Catherine Eckel, Shachar Kariv, Pedro Rey-Biel, Rupert Sausgruber, Marie-Claire Villeval, as well as participants at the Economic Science Association Meeting in Chicago and seminar participants at the universities of Erlangen-Nuremberg and Innsbruck and the Norwegian School of Economics and Business Administration in Bergen for helpful comments and suggestions. We gratefully acknowledge the help of Brent Cooper and Elisabetta Fratini from the International Judo Federation (IJF) who provided data and further assistance, and of Caroline Bonn who collected the questionnaires at the Judo Grand Prix in Amsterdam. Financial support from the Austrian Science Fund (FWF) through project P22772-G11 is gratefully acknowledged.
} 


\section{Introduction}

Tournaments such as races for job promotions, political office, or sports competitions are often plagued by sabotage among competitors. Instead of exerting positive effort to win the tournament, competitors may alternatively resort to sabotage, for instance through spreading malicious rumors about competitors, withholding important information, or by destroying a competitor's output. Sabotage is therefore typically welfare damaging, either in a direct way by reducing output or performance of competitors or indirectly if it reduces the agents' incentives to exert productive effort (Konrad, 2000; Carpenter et al., 2010; Harbring and Irlenbusch, 2011). While it seems obvious that sabotage is costly for organizations, it is due to its very nature hard to observe. Since sabotage is typically associated with illegal - or immoral - and punishable activities, those who engage in it will try to hide their activities. Therefore, it is hardly possible to collect clean, disaggregated data on sabotage at the individual level from organizations. Using the words of Charness and Levine (2004, p. 1), "because sabotage breaks rules it is difficult to study in the field".

So far, two prominent approaches have been used in the literature to examine sabotage empirically. The first one is to resort to controlled laboratory evidence, where sabotage can be observed by the experimenters. Several experiments have found that sabotage increases with the prize spread in a tournament (Harbring and Irlenbusch, 2005, 2008, 2011; Falk et al., 2008) and that sabotage has disincentive effects on tournament participants (Carpenter et al., 2011). Interestingly, Charness et al. (2011) have shown that sabotage can even occur in the absence of material incentives as a result of status-seeking behavior. The second approach is to use data from sports tournaments, where behavior is observable and well recorded. For instance, Garicano and Palacios-Huerta (2005) and del Corral et al. (2010) have studied how an increase in the points awarded for victory in soccer tournaments has affected the incidence of fouls, yellow cards (booking) and red cards (immediate dismissal) and the number of defensive players in a team. Their main finding has been that stronger incentives have increased the defensive play of teams and the incidence of fouls and thus yellow and red cards.

In this paper we also use data from a sports tournament, in particular from Judo World Championships, in order to examine the response of sabotage to changes in its cost structure, as well as its relationship with a number of personal characteristics such as (relative) ability and gender. To our knowledge, this is the first paper presenting field evidence on the interplay between the cost and the extent of sabotage. While previous experimental and field studies 
from soccer have examined how the prize for winning a contest affects sabotage activities, the cost side of sabotage has not received attention yet. From a legal perspective, however, it seems straightforward that jurisdictions are primarily concerned with how to determine penalties for sabotage and less so with intervening in the prize spread between winner and loser prizes in competitions. Likewise, organizations can easily adapt internal rules of conduct to change the expected cost of sabotage, for instance by monitoring more closely employees' activities or by threatening certain types of behavior with dismissal.

The use of data from Judo competitions has a number of advantages for the study of sabotage in tournaments. First, the rules are such that one can distinguish between "productive activities" aimed at winning the fight through a positive technical score, in the best case an Ippon (the equivalent of a knock-out in boxing), and "destructive activities" intended to hinder the opponent's attack, which are penalized (called shido) if they are judged to be against the rules of the game. We will treat such "destructive activities" as a form of sabotage. Second, a change in the rules, effective since 2009, has provided fighters with an opportunity for one costless act of sabotage. Comparing data before and after the rule change allows studying the impact of a different cost structure on the use of sabotage in what is in effect a natural experiment (List and Reiley, 2008). Third, Judo is an individual sport, which means that - contrary to soccer or other team sports - there is no public goods dimension to sabotage that may distort the incentives to execute sabotage. In the case of team sports, sabotage may be beneficial for the team as a whole, but detrimental to the team member executing it. Then, sabotage can be seen as contributing to a public good, with the usual free-rider problems linked to it. For this reason, Judo as an individual sport seems to be closer to the kind of tournaments that the literature on sabotage has typically occupied itself with, namely tournaments among individuals for jobs or promotions in the workplace.

On the basis of a unique dataset of 1,422 Judo fights from two consecutive World Championships - the last one before the rule change (2007) and the first one with the new rules (2009) - we have arrived at the following main results. First, we observe a considerable increase in the use of sabotage following the rule change in 2009. This indicates that Judokas responded to the change in the cost of sabotage in the expected way. Second, we find strong evidence that sabotage is more likely to be used by relatively less competent individuals, and to be targeted at more competent individuals. Competence is measured by means of the Judokas' world ranking. ${ }^{1}$ Third, we have examined the welfare implications of sabotage,

\footnotetext{
${ }^{1}$ This second finding is consistent with laboratory evidence from Charness et al. (2011), where sabotage is strongly negatively correlated with a subject's competence. Hence, our findings from the field are complementary to experimental evidence and support the experiment's external validity.
} 
complementing our dataset with a survey administered on 115 spectators of a Judo Grand Prix. The competition data and survey responses clearly support the welfare reducing effect of shido, implying that the rule change in 2009 had a negative impact on spectator welfare.

The findings of this paper can be extended beyond the domain of sports, given that there is a close link between on- and off-the-field behavior of athletes, and there is an increasing mutual transmission of values and patterns of behavior between sports and other areas of society (Eitzen, 1999). More generally speaking, our findings can help advance the understanding of various factors that determine how individuals resort to sabotage. The evidence that sabotage responds to changes in its cost for the saboteur is useful information for the way in which internal control mechanisms are set up in the workplace. Much in line with Becker's (1968) theory on crime and punishment, our data suggest that rule-breaking behavior can be discouraged through increases in the penalties - and hence in the expected cost of such behavior. On a different issue, our results relate sabotage to ability and suggest that the more competent individuals are also more likely to be its victims. Of course, this is bad news for aggregate productivity, if the output of the most productive members of an organization is targeted by counterproductive activities.

The rest of the paper is organized as follows. In section 2 we give some background information on Judo and its rules, including details on our measure of sabotage in this context and on the recent rule change. Section 3 presents our dataset and the main results of the paper. Section 4 concludes.

\section{Judo: General information and rules}

\subsection{A noble sport with a long history}

While the origin of Judo as the "gentle way" of self-defense is rooted in the ancient martial art of Jiu Jitsu, Judo was established as a genuine sport in Japan in 1882, and it has been an Olympic Sport since 1964. Today, the International Judo Federation (IJF) has 200 member nations, and participants in World Championships or Olympic Games are typically paid professionals. Demanding high standards of the athletes in terms of skill, technique and timing, Judo can be regarded as one of the most challenging sports regarding physical strength and agility. Beyond that, however, respectfulness, self-discipline and the aspiration towards improvement are the basic ideals, which constitute the so-called "Spirit of Judo" according to the statutes of the IJF (see www.ijf.org). These basic principles should not only govern the Judokas' behavior in sporting competitions, they should also translate into guidelines for 
everyday life. As mentioned in the preamble of the IJF statutes, "Judo is a [...] sport in which the mind controls the expression of the body and is a sport which contributes to educating individuals". ${ }^{2}$

\subsection{Description of the basic rules}

The rules of Judo are set by the IJF and enforced by three referees in every fight. ${ }^{3}$ There are four different types of scores awarded for positive effort: ranked from highest to lowest they are called Ippon, Waza-ari, Yuko and Koka. These scores are given for legitimately throwing or holding the opponent on his back on the mat with control (Osaekomi-waza). An Ippon is given for a perfectly executed technique, a 25-second Osaekomi-waza, or in case a contestant gives up, and it leads to immediate victory (equivalent to a knock-out in boxing). A Waza-ari is awarded when one of the elements of the throwing technique is missing, or when the Osaekomi-waza lasts for 20-24 seconds. Two Waza-ari sum up to an Ippon and thus lead to immediate victory. When two elements are missing from the technique, e.g., when one throws his opponent on his side, or holds him down for less than 20 seconds, a Yuko is awarded. Finally, the lowest score (Koka) is given when one contestant with control throws the other onto one shoulder, his thigh(s), or buttocks, or by Osaekomi-waza for 10 to 14 seconds.

The scores are lexicographic, so that - unless a fight has already been decided by an Ippon or two Waza-ari - the winner is the fighter with the score of higher rank at the end of the fight. In other words, no matter how many Yuko, respectively Koka, one collects, their score will be inferior to one Waza-ari, respectively one Yuko.

In addition to these positive scores, penalties are given to fighters who breach the rules of contest. There are two types of penalties, called shido and Hansoku-make. For a slight infringement, a contestant receives a penalty of shido, which is automatically converted into a positive score in favor of the opponent. The first shido leads to a Koka for one's opponent, the second one replaces this Koka with a Yuko, and so on (see Table 1). It is then obvious that, when a fighter picks up four shido, he immediately loses the fight since the four penalties sum up to an Ippon for his opponent. Grave infringements are punished with the penalty of Hansoku-make, which results in direct defeat as well as disqualification from the entire tournament. Actions that are dangerous for the opponent or the athlete himself are classified as grave infringements.

\footnotetext{
${ }^{2}$ See http://www.ijf.org/editor_up/up/STATUTS_angol.pdf.

${ }^{3}$ See http://www.ijf.org/IJF_Referee_Rules/English_Version_/English_Version.
} 


\section{Table 1 about here}

The regular contest time (at the adult level) is five minutes if none of the fighters manages to score an Ippon. In the event of a tie, a "golden score" rule is applied, which means that the fight continues and the first athlete who picks up a positive score is declared the winner of the fight. In all Judo tournaments, contestants are divided into seven weight classes per gender, ranging from $60 \mathrm{~kg}$ or less (extra light weight) to $100 \mathrm{~kg}$ or more (heavy weight) for men, and from $48 \mathrm{~kg}$ or less to $78 \mathrm{~kg}$ or more for women. The competitions in each weight class are held on a single day. The tournament format in Judo is called elimination system with double repêchage. The Judokas are placed by random drawing in two tables and an elimination system is used to determine the two finalists in each weight class. The contestants previously defeated by the four semi-finalists take part in the repêchage (i.e., the "second chance") of their respective table, and they fight for the bronze medal against the loser of the semi-final fight of the other table. The latter rule implies that two bronze medals are awarded.

The rules underwent a considerable change by the IJF at the beginning of 2009: Koka, the previously lowest score, was abolished, turning Yuko into the lowest score as of January $1^{\text {st }}, 2009$. As a consequence, the first collected shido became a free warning under the new rules (see Table 1). Since we will interpret shido as sabotage, the free warning is seen as equivalent to one opportunity for a costless act of sabotage, which we will exploit when we analyze individual behavior in section 3.2 .

\subsection{The shido as an act of sabotage}

As already mentioned above, the shido is a penalty given for an infringement of the rules of Judo. We believe that the shido should be seen as an act of sabotage. Based on the definition of Lazear (1989), sabotage in a competition refers to "any (costly) actions that one worker takes that adversely affect the output of another" (p. 563). In the context of a Judo fight, the shido is the result of a - typically costly - action taken by one Judoka in order to adversely affect the opponent's productive effort, which in this case is his positive technical score. For example, a shido is given when a fighter "kicks the hand or arm of the opponent to make him release his grip", "bends back the opponent's finger in order to bend his grip", "adopts an excessively defensive posture", takes various actions that "prevent action in the contest", shows "non-combativity", "holds the opponent's sleeve end(s) for a defensive purpose", goes 
outside of the contest area, etc. ${ }^{4}$ These actions are clearly aimed at illegitimately hindering the opponent's attack, thereby reducing the opponent's chances at improving his output through a positive technical score, without contributing anything to one's own technical score. In section 3.2 we will examine how the change in the cost of the first shido since 2009 has affected the likelihood of shido. Our hypothesis is that a cost reduction will lead to more shido.

Another feature of sabotage is that, by reducing the opponent's productive output, it aims at increasing one's chances of winning a competition. A shido can be interpreted in this way, as it may prevent a direct defeat through Ippon. Notice that, as long as the fight is continuing, it is always possible for the fighter lagging behind in terms of technical scores to win the match, even in its last second, if he manages to score an Ippon. This is due to the lexicographic winning rule. In that sense, a shido allows a fighter to stay in the game by avoiding a knock-out move by his opponent, and therefore can be seen as an effort to increase one's chances of winning. In section 3.3 we will analyze how a fighter's and his opponent's ability are related to the use of shido, thus examining in particular at whom sabotage is targeted. Our hypothesis is that shido should be more often employed by less qualified and more often targeted at more qualified subjects.

One last important feature that must be taken into account when drawing the parallel between sabotage in Judo and sabotage in organizations is the effect of sabotage on welfare. In section 3.4 we will use the occurrence of positive scores resulting from legitimate attacking techniques as a proxy for spectator welfare, and we will show that shido are indeed welfare reducing.

\section{Results}

\subsection{Structure of the dataset and summary statistics}

Our dataset includes all fights from the World Championships of 2007 (held in Rio de Janeiro) and 2009 (held in Rotterdam). We chose the World Championships because they are the largest and most important international competitions for which data are available under the old as well as under the new rules. The Olympic Games are arguably the most prestigious competition, but they have not yet taken place under the new rules.

\footnotetext{
${ }^{4}$ Source: http://judoinfo.com/penalty.htm.
} 
With the help of IJF employees, we were able to collect data on all 1,422 fights that took place in both World Championships. This means we have 2,844 observations, since each fight provides data on the individual behavior of two Judokas. Each observation consists of the following variables: personal information (name, gender, age, nationality, position in world rankings, weight class), summary information about the fight (duration, final score, winner, winning technique, golden score), and detailed information on the timeline of the fight. The latter includes the scores and penalties given to a fighter and the precise time (in seconds) at which an event occurred. For reasons of comparability and consistency across fights, we restrict ourselves to the first five minutes in each fight, meaning that for the 99 fights (out of 1,422) that were decided after golden score we only consider events during regular time. ${ }^{5}$

Table 2 presents summary statistics, broken down by tournament ${ }^{6}$ and including in its third column also the total figures. The first six rows refer to the score that was pivotal for determining the winner, i.e., the score that made the difference between the two fighters. While we see that the majority of fights ended abruptly with an Ippon (about 60\%), a sizeable share of about $33 \%$ of fights was decided based on the score after the five minutes of regular contest time. About $7 \%$ of fights were tied after five minutes and thus decided by golden score.

\section{Table 2 about here}

For each score, we have data on whether it was the result of a fighter's own (positive) effort or the result of one or more shido given to the opponent. This allows us to identify those fights in which shido was pivotal for the outcome, in the sense that the decisive difference in the final scoreline between the two opponents was the result of a shido. The sixth row of Table 2 shows that these fights account for approximately $13 \%$ of the total number of fights.

\footnotetext{
${ }^{5}$ We also exclude fights in which one of the two contestants either did not turn up or forfeited due to injury.

${ }^{6}$ Note that before 2009, all losers to the four semi-finalists were allowed into the repêchage, while since 2009 only the losers in the quarter-finals were admitted to the repêchage. As a consequence, there have been fewer fights in the repêchage since 2009. This is one of the reasons why we have fewer observations from 2009 than from 2007 in our dataset. We have examined the robustness of our results if we apply the repêchage-rules since 2009 to the 2007-data and have found qualitatively the exact same results. These robustness checks are available upon request.
} 


\subsection{Consequences of changing the cost of shido in 2009}

Since 2009, every fighter has the opportunity for one costless shido. In other words, the marginal cost of the first shido is zero, but from the second shido onwards the marginal as well as total cost is the same as under the old rules. Hence, if fighters react to the rule change, we should observe fewer cases where a fighter commits no shido at all. As Figure 1 shows, the proportion of fighters who did not commit any shido dropped sharply after the rule change, from $66.3 \%$ to $42.3 \%$ ( $p=0.000, \chi^{2}$ test). Accordingly, the mean number of shido increased under the new rules, from 0.46 to 0.99 per observation ( $p=0.000$, Mann-Whitney test). This finding is also supported by econometric evidence presented in section 3.3. Thus, exploiting the recent rule change allows us to formulate the first finding of our paper: individuals react to lower costs of sabotage by increasing its use.

\section{Figure 1 about here}

Looking at the rule change from a slightly different angle, the set of costless shido increased from $\{0\}$ in 2007 to $\{0,1\}$ in 2009. When we compare the number of observations with zero shido in 2007 against those with zero or one shido in 2009, we find that the proportions are not significantly different from each other (66.3\% vs. $69.7 \% ; p=0.259, \chi^{2}$ test). This provides further support for our hypothesis that individuals take the cost of sabotage into account when deciding on their strategies and that they react as predicted to changes in the cost structure.

Despite being much lower than in 2007, the proportion of observations with zero shido in 2009 still seems surprisingly high at $42.3 \%$. When given the opportunity for one costless shido, why would not all fighters take advantage of it? Part of the answer lies in the fact that many fights are decided by Ippon before the 5 minutes of regular contest time are over, so that fighters often do not pick up a shido, although they might have done so in the full course of a fight. In fact, $59.5 \%$ of all fights in our sample were decided by Ippon. If we exclude these fights and recalculate the proportions shown in Figure 1, the proportion of zero-shido observations in 2009 is only half as high as before, at $23.3 \%$. The corresponding figure in 2007 is again significantly higher than in 2009 , at $49.6 \%\left(p=0.000, \chi^{2}\right.$ test $)$.

While we have correctly anticipated that the number of observations with zero shido would decline in 2009 and that, accordingly, the mean number of shido would increase, it is not clear how the rest of the distribution (i.e., observations with more than one shido) should look like under the new rules. If individuals had perfect foresight into the future and could 
choose optimally the number of shido that maximizes their chances of winning a given fight, then the number of fights with two or more shido should not differ across the two rule regimes, because there is no difference in the cost of the second, third or fourth shido. In other words, we should only observe a shift from the first bar in Figure 1 (zero shido) towards the second bar (one shido). However, while the proportion of observations with one shido has indeed increased significantly, albeit only mildly ( $23.7 \%$ vs. $27.4 \% ; p=0.027, \chi^{2}$ test), there has been a large increase in the cases of two, three or four shido (10\% in 2007 vs. $30.3 \%$ in 2009; $p=0.000, \chi^{2}$ test).

An explanation for this pattern could be the following. If the first shido is costless, a fighter might be more likely to resort to it the first time that he finds himself in a difficult situation, instead of risking a positive score (in the worst case an Ippon) for his opponent. If this conjecture holds true, a fighter may continue picking up additional shido depending on the situation and the needs of his strategy, so that, in the end, we end up with a pattern like the one shown in Figure 1.

In order to pursue this line of reasoning, we look at the mean time that it takes a Judoka to resort to a shido for the first time during a fight. Indeed, we find that the mean time to the first shido (conditional on there being at least one) falls from 138.9 seconds under the old rules in 2007 to 107.4 seconds in 2009 ( $p=0.000$, Mann-Whitney test). Another way of looking at this is by means of the cumulative distribution function of the time to the first shido over the 300 seconds of a fight. Figure 2 shows the results. The 2009 distribution stochastically dominates that of 2007, confirming that sabotage was used earlier after the introduction of the new rules in 2009 . $^{7}$

Figure 2 about here

In order to account for the possibility that the increase in sabotage between 2007 and 2009 is due to a general trend in Judo - and not due to the rule change in 2009 -, we collected data on the average number of shido per observation for the World Championships from 1995 to 2005. The evolution over time is shown in Figure 3. It turns out that the mean number of shido was actually showing a downward trend between 2003 and 2007, i.e., before the rule change. Then, after the rule change in 2009 , this trend was reversed and we observe the strong surge documented in our data. Thus, we can confidently say that the observed increase in the

\footnotetext{
${ }^{7}$ In the appendix we also show (in Figure A1) the cumulative distribution function of the occurrence of any shido (not just the first one). Again, the distribution for 2009 first-order stochastically dominates the distribution for 2007, confirming that shido were used, in general, earlier after the rule change in 2009.
} 
number of shido per observation in 2009 has not been the result of a general upward time trend and that, if anything, this increase may be underestimating the true effect of the rule change.

\section{Figure 3 about here}

In addition to the number of shido per fighter, we also present in Figure 3 the evolution of the time to the first shido, to rule out the possibility that our findings are due to time trends. The pattern is qualitatively the same: the time to first shido was actually showing an upward trend between 2003 and 2007, before falling sharply in 2009 after the rule change. Hence, our data strongly support the finding that the natural experiment of making the first shido costless since 2009 has led to more shido and to an earlier use of them.

\subsection{Sabotage and competitors' qualification}

Next we are going to examine how the use of sabotage is related to the competitors' qualification and other characteristics. In order to create a measure of the Judokas' qualification or competence, we reconstructed every fighter's position in the world ranking list at the time when a tournament took place (i.e., in 2007 or 2009). The world ranking list is based on each fighter's four best results during the most recent two-year period, with points allocated on the basis of performance in a tournament, adjusted for the importance of the tournament. Using this ranking, we then created a normalized measure of an athlete's ability within the weight class that he or she is competing in a given competition. This variable, called ability, is 0 for the lowest-ranked athlete in a weight class and 1 for the highest-ranked athlete. $^{8}$

Looking at the correlations between ability and the number of shido, we document that the latter is increasing in the opponent's ability (correlation between opponent's ability and own number of shido: $\rho=0.15, p=0.000$ ). This result suggests that sabotage is more likely to be targeted at the more competent individuals in a tournament. At the same time, we find a negative correlation between own ability and number of shido, which implies that sabotage is more likely to come from less competent individuals, all else equal $(\rho=-0.04, p=0.039)$.

The two ordered probit regressions in Table 3 explain the use of sabotage (number of shido) based on a fighter's own ability, on his (her) opponent's ability, the rule regime (old

\footnotetext{
${ }^{8}$ The ability measure is defined exactly as $1-(\operatorname{rank}-1) /(n-1)$, where $n$ is the number of participating fighters and rank a fighter's ordinal ranking within the set of participants.
} 
versus new rules) and the athlete's gender. Both specifications use standard errors clustered by fight, to account for the fact that the two observations per fight are not independent of each other.

\section{Table 3 about here}

The first noteworthy result is that the regressions confirm the strong positive response of the use of shido to the lower cost under the new rule regime (coefficient on the variable new rules). Moreover, in model (1) we see a significantly negative (positive) effect of own (opponent) ability on the number of shido committed, with the effect of the opponent's ranking being substantially stronger than that of an athlete's own ranking. In model (2), the effects of own and opponent's ability on sabotage are given by the joint coefficients, ability + ability * new rules, respectively opponent's ability + opponent's ability * new rules. Both of these joint coefficients are statistically significant at the $1 \%$ level according to a Wald-test. The insignificant interaction terms reveal that the reaction of athletes to the rule change did not vary by ability level. Our results also show that there is no significant gender effect in the use of sabotage, nor is the reaction of women to the introduction of the new rules statistically distinguishable from that of men (captured by the insignificant interaction term female*new rules in the second column).

\subsection{Welfare effects of the shido}

So far, our results draw a clear pattern. With the introduction of the new rules in 2009 , the use of shido became more frequent. But what are the welfare implications of this rule change? Such a question does not have an obvious answer in the context of a sports tournament. Since we are dealing with a zero-sum game between the two Judokas, we can abstract from their welfare - which arguably only depends on victory. Instead, we examine how spectators perceive the game and how changes in the number of shido affect their welfare.

To this end, we have conducted a survey among spectators of a major Judo tournament, the Judo Grand Prix ${ }^{9}$ held in November 2011 in Amsterdam. A research assistant collected survey responses from 115 spectators. The full questionnaire and mean answers are given in the appendix.

\footnotetext{
${ }^{9}$ The hierarchy of Judo tournaments (with respect to the number of points that can be gained for the world ranking) is Olympic Games, World Championships, Grand Slam, Grand Prix, World Cups and Continental Championships.
} 
Our conjecture is that spectators dislike shido, and that they prefer to watch actions and techniques by the two athletes leading to the award of positive scores; after all, these techniques are what Judo is about. On the contrary, scores awarded on the basis of shido do not provide any sort of spectacle and normally should not add to the satisfaction of the audience. The survey responses to three key questions confirm this intuition. On a scale of 1 to 5 - where 1 indicates strong disagreement and 5 strong agreement - the mean response to the item "I would like to see as many shido in a fight as possible" is 1.47. Conversely, the mean response to the item "I prefer to see Waza-ari and Yuko that are the result of an attack, not the result of a shido" is 4.16, and the item "I am happy when a fight is decided by Ippon" collects a mean response of 4.55 .

Accordingly, in order to assess the impact of the increased use of shido since 2009 on spectator welfare, we compare the share of fights that were decided through positive scores (Ippon, Waza-ari or Yuko) in 2007 and in 2009 (see Table 1). ${ }^{10}$ It turns out that there was a significant drop in this share between 2007 and 2009, from 79.6\% to 75.1\% ( $p=0.049, \chi^{2}$ test). Similarly, if we compare the total number of these positive scores awarded during the course of a fight in 2007 and 2009, we find that it decreased from an average of 1.31 scores per fight to an average of 1.21 scores per fight ( $p=0.044$, Mann-Whitney test). Combined with the survey responses, these findings suggest negative welfare effects of the shido when one defines welfare in terms of spectator satisfaction, and hence they lend further support to our view of shido as a means of costly, welfare-reducing sabotage in a tournament.

\section{Conclusion}

In this paper, we have examined how the individual use of sabotage responds to changes in its cost structure. While previous experimental and field studies from soccer have examined how the prize for winning a contest affects sabotage activities (Harbring and Irlenbusch, 2011; del Corral et al., 2010), the cost side and its influence on the incidence of sabotage has not received attention yet. Hence, we consider our paper as the first one presenting field evidence on the interplay between the cost and the extent of sabotage.

We have exploited a natural experiment in Judo that arose as the result of a rule change in the cost of sabotage activities from 2009 onwards. Prior to this date, illegitimate techniques were punished immediately, while since 2009 the first infringement of rules has

\footnotetext{
${ }^{10}$ We do not include fights that were decided through Koka, as this was not possible in 2009.
} 
been treated by a costless warning. We have interpreted the shido in Judo as an act of sabotage. According to Lazear (1989), sabotage in a competition refers to "any (costly) actions that one worker takes that adversely affect the output of another" (p. 563). In the context of a Judo fight, the shido is the result of a - typically costly - action taken by one Judoka in order to adversely affect the opponent's productive effort that aims at receiving a positive technical score.

Based on 1,422 fights from two Judo World Championships in 2007 and 2009 we have found that the change of rules in 2009 has increased the number of shido significantly. As an important complementary result we have also found that the time to the first shido has been reduced by about 30 seconds, leading to more observations of two or more shido. As a consequence, the relative frequency of fights that are decided by negative scores through shido has increased from $10.6 \%$ in 2007 to $17.3 \%$ in 2009 ( $p=0.000, \chi^{2}$ test). The reverse side of this finding is that fewer positive scores have been observed in 2009 than in 2007. From a survey among spectators we have reasons to believe that fewer positive and more negative scores are welfare reducing from the viewpoint of spectators. Hence, the rule change by the International Judo Federation has not only changed the characteristics of fights (more and quicker shido; fewer positive scores), but arguably also the perception and well-being of spectators. Therefore it seems well justified to summarize that the change in the cost of sabotage has had a profound impact on the tournament.

We have also found that sabotage activities are significantly more often targeted at more qualified agents, measured by means of a Judoka's world ranking, and they are less often used by better Judokas. This is certainly an intuitive finding. However, it is exactly the type of finding that worries organizations around the globe, namely that destructive activities will negatively affect the best performers, something that can bear high costs for the profits of a company, or - in a different context - for the quality of candidates in electoral campaigns. Our field study has provided strong evidence that these worries may be well justified. Moreover, we have shown that the worries will be exacerbated if the costs of sabotage are reduced, since agents react systematically to incentives, such as a change in sabotage costs. For this reason, internal control mechanisms in companies that try to monitor and discourage sabotage are very important to prevent losses in productivity that may arise if the output of the most productive members of an organization is targeted by counterproductive activities. 


\section{References}

Becker, G., 1968. Crime and punishment: An economic approach. Journal of Political Economy 76: 169-217.

Carpenter, J., Matthews, P., Schirm, J., 2010. Tournaments and office politics: Evidence from a real effort experiment. American Economic Review 100: 504-517.

Charness, G., Levine, D.I., 2004. Sabotage! Survey evidence on when it is acceptable. Center for Responsible Business, UC Berkeley Working paper no. 12.

Charness, G., Masclet, D., Villeval, M.C., 2011. Competitive preferences and status as an incentive: Experimental evidence. GATE Working Paper no. 1016.

Chen, K.P., 2003. Sabotage in promotion tournaments. Journal of Law, Economics, and Organization 19: 119-140.

del Corral, J., Prieto-Rodriguez, J., Simmons, R., 2010. The effect of incentives on sabotage: The case of Spanish football. Journal of Sports Economics 11: 243-260.

Eitzen, S., 1999. Fair and foul: Beyond the myths and paradoxes of sport. $4^{\text {th }}$ edition. Lanham, MD: Rowman \& Littlefield.

Falk, A., Fehr, E., Huffman, D., 2008. The power and limits of tournament incentives. University of Bonn Working Paper.

Garicano, L., Palacios-Huerta, I., 2005. Sabotage in tournaments: Making the beautiful game a bit less beautiful. CEPR Discussion Paper no. 5231.

Harbring, C., Irlenbusch, B., 2005. Incentives in tournaments with endogenous prize selection. Journal of Institutional and Theoretical Economics, 161: 636-663.

Harbring, C., Irlenbusch, B., 2008. How many winners are good to have? On tournaments with sabotage. Journal of Economic Behavior and Organization 65: 682-702.

Harbring, C., Irlenbusch, B., 2011. Sabotage in tournaments: Evidence from a laboratory experiment. Management Science 57: 611-627.

Harbring, C., Irlenbusch, B., Krakel, M., Selten, R., 2011. Sabotage in asymmetric contests: An experimental analysis. International Journal of the Economics of Business, forthcoming.

Konrad, K., 2000. Sabotage in rent-seeking contests. Journal of Law, Economics and Organization 16: 155-165.

Lazear, E., 1989. Pay equality and industrial politics. Journal of Political Economy 97: 561580.

List, J. A., Reiley, D., 2008. Field experiments. In: Durlauf, S. N., Blume, L. E., (eds.) The New Palgrave Dictionary of Economics. Second edition. Palgrave Macmillan. 
Skaperdas, S., Grofman, B., 1995. Modeling negative campaigning. American Political Science Review 89: 49-61. 


\section{Tables and Figures}

Table 1: Conversion of shido into positive scores

\begin{tabular}{cccc}
\hline \hline & & 2007 & 2009 \\
shido \#1 & translates into: & Koka & free warning \\
shido \#2 & $>>$ & Yuko & Yuko \\
shido \#3 & $>>$ & Waza-ari & Waza-ari \\
shido \#4 & $>>$ & Ippon & Ippon \\
\hline \hline
\end{tabular}


Table 2: Summary statistics. Reported values are numbers of fights, percentages over total in brackets

\begin{tabular}{lccc}
\hline \hline pivotal score & $\mathbf{2 0 0 7}$ & $\mathbf{2 0 0 9}$ & Total \\
\cline { 2 - 4 } Ippon & $511(58.9)$ & $335(60.4)$ & $846(59.5)$ \\
Waza-ari & $80(9.2)$ & $38(6.8)$ & $118(8.3)$ \\
Yuko & $99(11.4)$ & $44(7.9)$ & $143(10.1)$ \\
Koka & $27(3.1)$ & $\mathrm{n} / \mathrm{a}$ & $27(1.9)$ \\
Hansoku-make & $1(0.1)$ & $0(0.0)$ & $1(0.1)$ \\
shido & $92(10.6)$ & $96(17.3)$ & $188(13.2)$ \\
\hline fight ended in draw & $57(6.6)$ & $42(7.6)$ & $99(7.0)$ \\
\hline total number of fights & 867 & 555 & 1,422 \\
\hline women's fights & $356(41.1)$ & $223(40.2)$ & $579(40.7)$ \\
\hline \hline
\end{tabular}


Table 3: Sabotage and athletes' characteristics

Dependent variable: number of shido. Ordered probit regressions, dependent variable takes integer values between 0 and 4 .

(1)

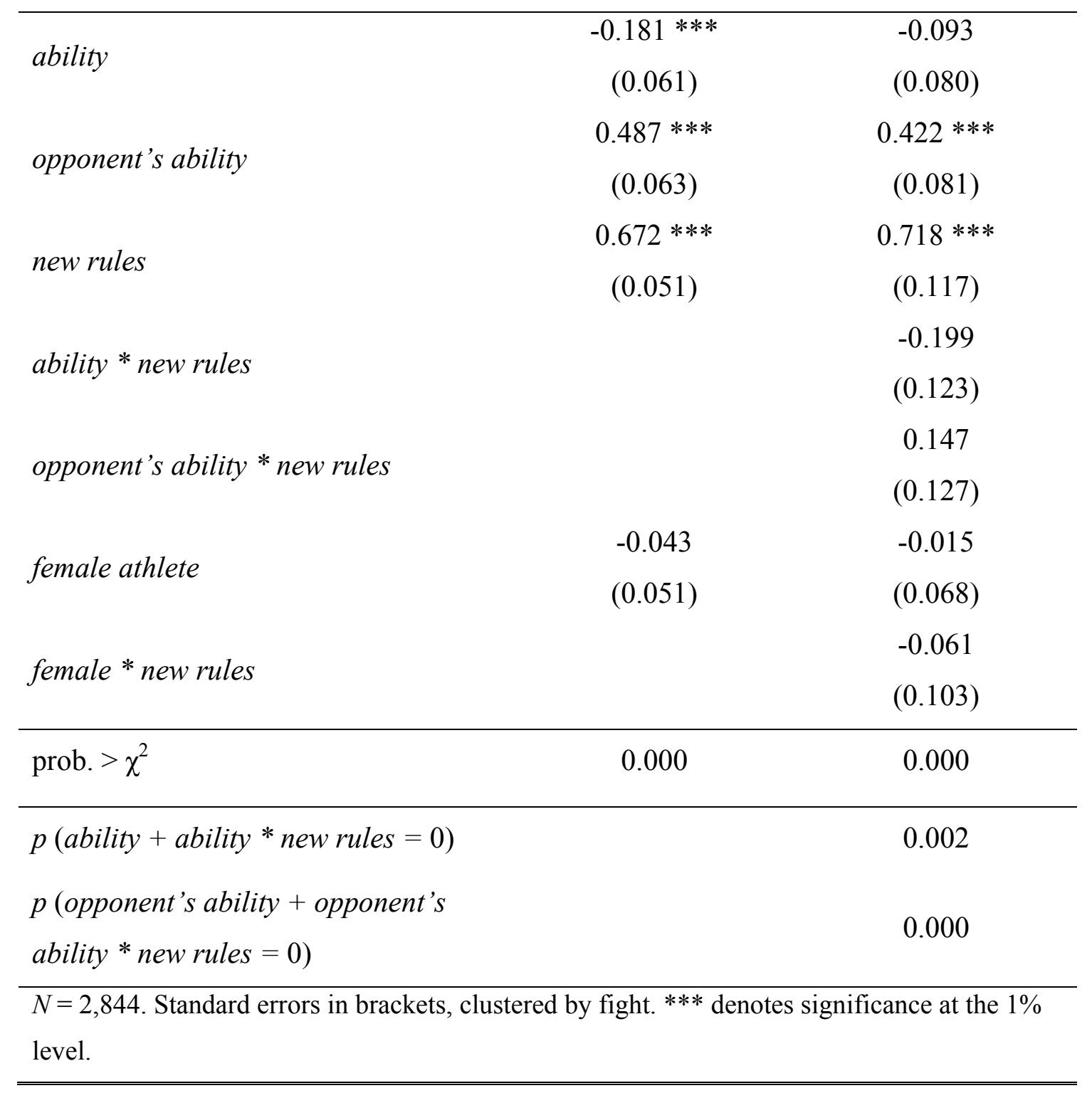


Figure 1: Distribution of the number of shido per observation, by rule regime

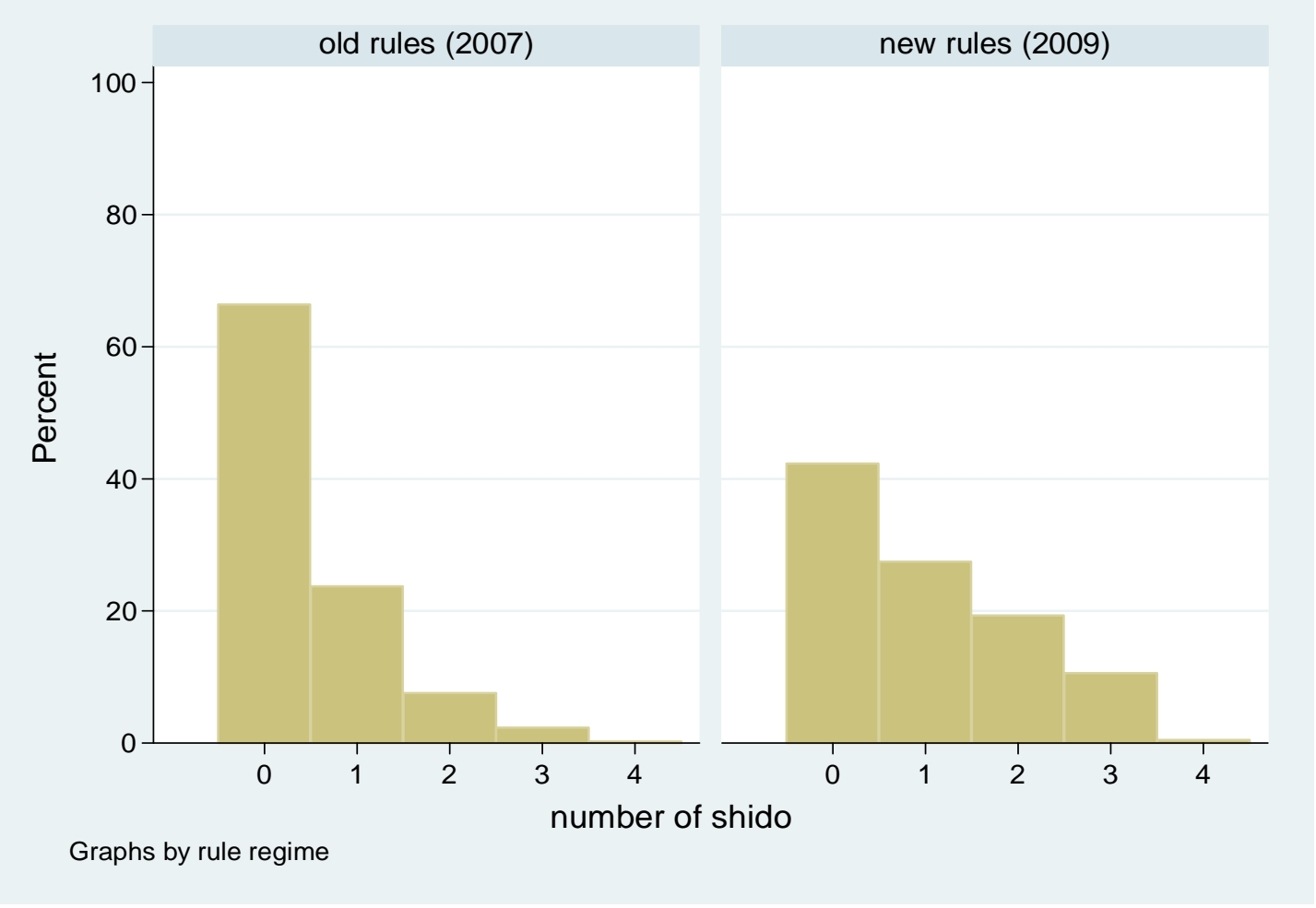


Figure 2. Cumulative distribution functions of first shido during the course of the fight, 2007-2009.

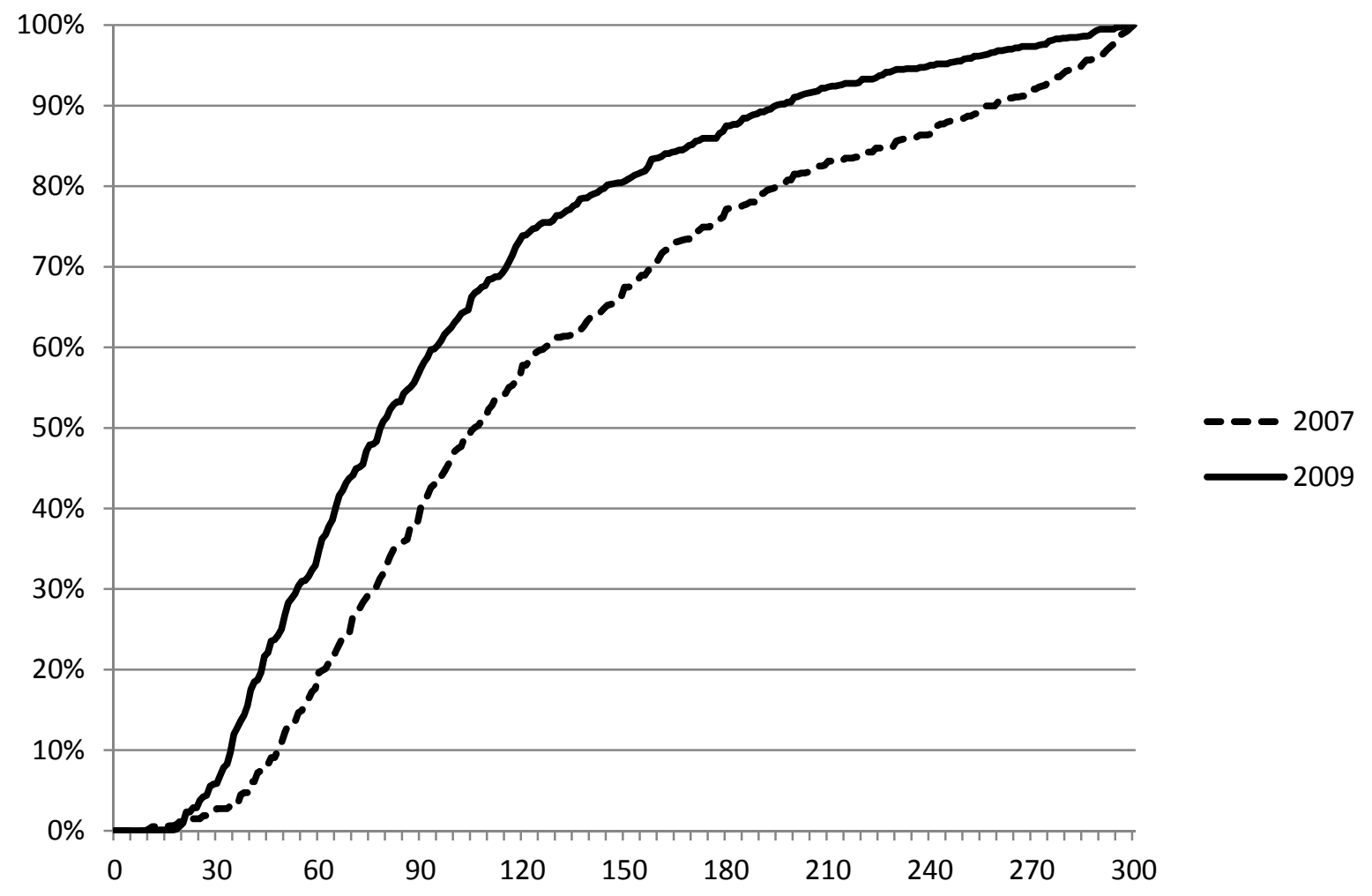


Figure 3: Evolution of number of shido and time to first shido, World Championships 1995-2009

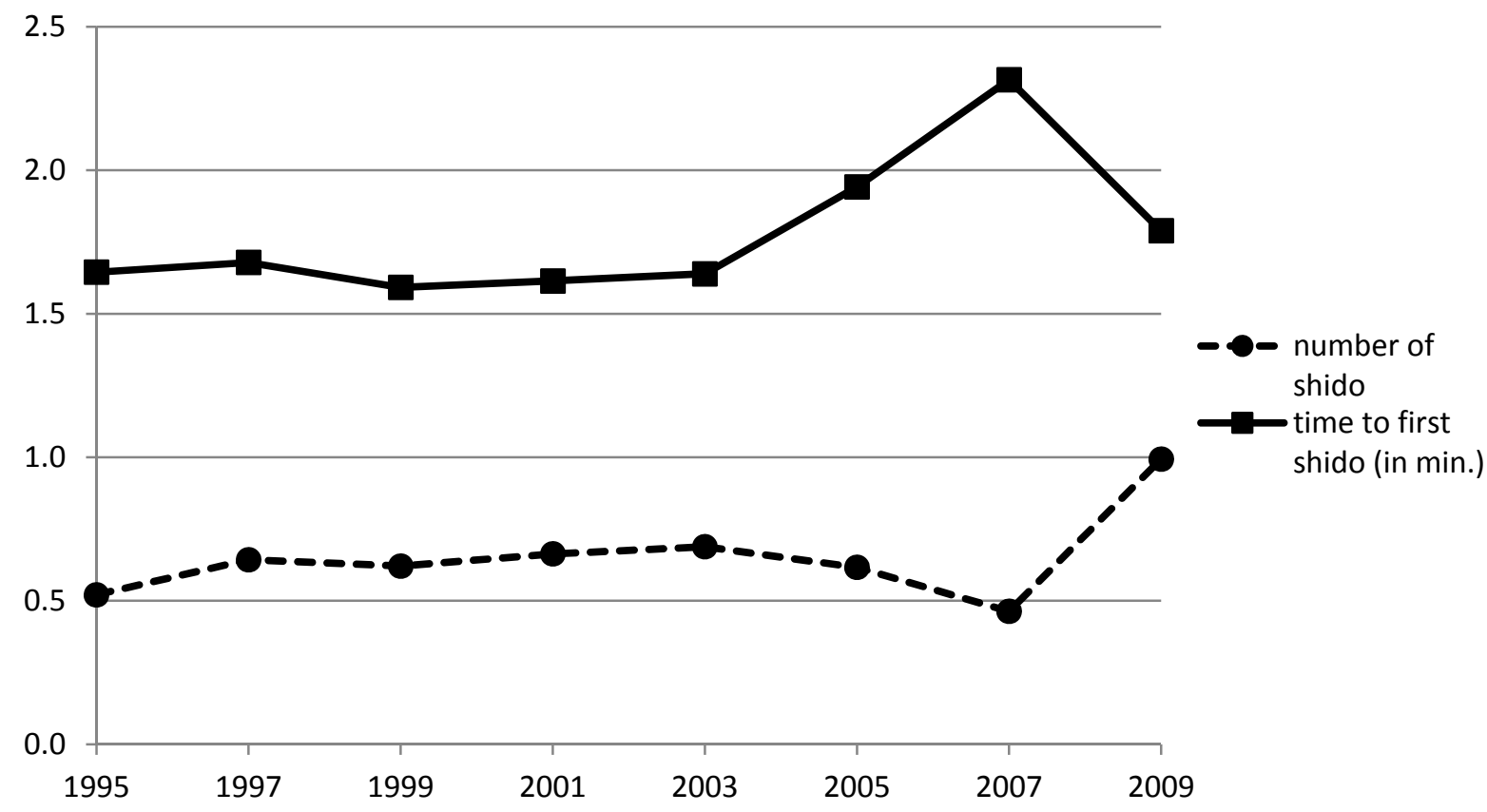




\section{Appendix}

Spectator Survey [including mean response values and number of observations per response]

Good morning/afternoon. We are a research team from the University of Innsbruck, Austria. In agreement with the IJF, our team is conducting a survey on Judo.

We would be grateful if you could spare 2-3 minutes to answer a few questions about your views on Judo and some of its rules.

1. Please indicate the following: $(N=115)$

Age: (mean age: 37.5 years)

Gender (male/female):

Nationality:

2. Are you familiar with the rules of Judo? $(N=115)$

\begin{tabular}{|l|c|}
\hline No, not at all & $5 \%$ \\
\hline Only a little & $21 \%$ \\
\hline Quite familiar & $24 \%$ \\
\hline Very familiar & $50 \%$ \\
\hline
\end{tabular}




\section{3. [If the answer to (1) is other than NO, NOT AT ALL]:}

As a neutral spectator, state the degree of your agreement/disagreement with each of the following statements on a scale of 1 to 5 (where 1=strongly disagree; 2=disagree; 3 = neither agree, nor disagree; $4=$ agree; $5=$ =strongly agree)

\begin{tabular}{|l|c|}
\hline I am happy when a fight is decided by Ippon & $4.55(N=83)$ \\
\hline $\begin{array}{l}\text { I would like to see as many Waza-ari and Yuko in a fight as } \\
\text { possible }\end{array}$ & $3.60(N=82)$ \\
\hline $\begin{array}{l}\text { I prefer to see Waza-ari and Yuko that are the result of an attack, } \\
\text { not the result of a shido }\end{array}$ & $4.16(N=82)$ \\
\hline $\begin{array}{l}\text { I usually prefer the underdog to win and advance to the next round, } \\
\text { and not the favorite }\end{array}$ & $2.65(N=81)$ \\
\hline $\begin{array}{l}\text { I do not mind it when the fighters are very defensive or try to avoid } \\
\text { action }\end{array}$ & $2.12(N=81)$ \\
\hline I would like to see as many shido in a fight as possible & $1.47(N=81)$ \\
\hline $\begin{array}{l}\text { When there is an attacking move, I usually want it to be successful } \\
\text { I prefer to watch fights between famous Judokas, and not between } \\
\text { outsiders }\end{array}$ & $3.90(N=81)$ \\
\hline
\end{tabular}

4. How often have you attended Judo tournaments in the past? $(N=115)$

\begin{tabular}{|l|c|}
\hline Never before & $17 \%$ \\
\hline 1 time & $9 \%$ \\
\hline $2-4$ times & $16 \%$ \\
\hline$>4$ times & $59 \%$ \\
\hline
\end{tabular}

\section{Have you ever practiced Judo yourself? $(N=115)$}

\begin{tabular}{|l|c|}
\hline No, never & $34 \%$ \\
\hline Yes, but only at an amateur level & $50 \%$ \\
\hline Yes, at a professional level (took part in national competitions) & $17 \%$ \\
\hline
\end{tabular}


Figure A1: Cumulative distribution functions of all shido during the course of the fight, 2007-2009

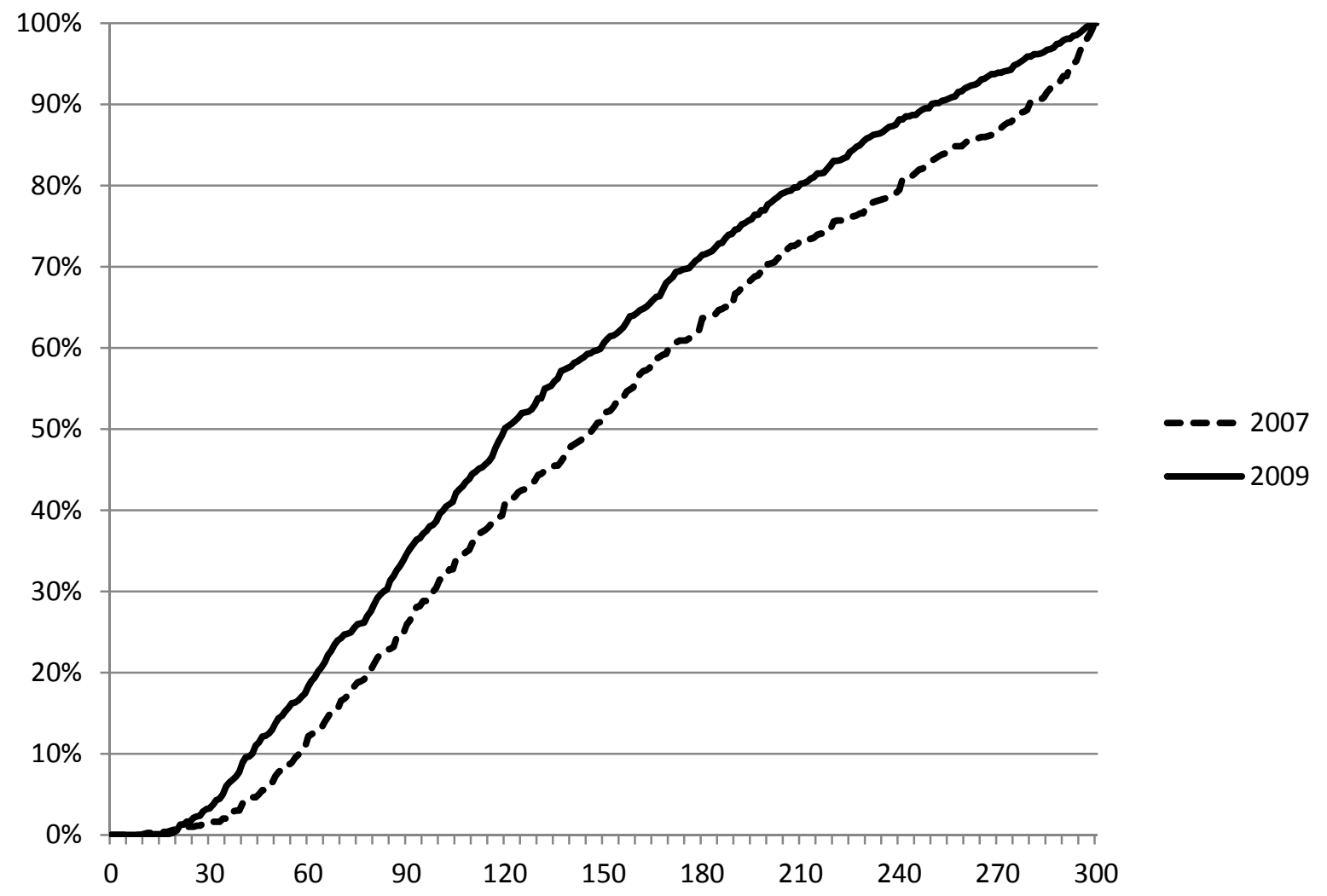

